Kristina Kuhn

\title{
Reading by Grouping: Collecting Discipline(s) in Brockhaus's Bilder-Atlas
}

As a perspective on its material that is documented (and documents itself) in case studies, research into cultural techniques has a decisive advantage over an analysis of multimedia formations and contexts that is grounded purely in media studies: it makes it possible to switch between the perspectives of construction/production and reconstruction/reception while also considering technical, social, and mental constellations. Some of the contributions in this volume are particularly concerned with interrelations and interactions between cultural techniques and literature as a collection - though not only of letters (litterae) but also of quotations, excerpts, and other media. The scene of writing binds literature to its material, paper, and writing implement (or virtual surfaces), as well as to the movement(s) of the hand (writing, typing, or browsing, which are in a certain sense techniques of the body).

My research material, which draws from encyclopedic corpora, i.e., from a cluster of textual and visual bodies, as well as from bound volumes and their supplements, does not form literature in a classic sense. Even though encyclopedias carry out excessive practices of collecting, collectivizing, or making available to a collective, they find relatively few readers. Neither their articles and indexes nor their legends and lists allow for a linear reading guided by a consistent sense or coherent narrative. Indeed, this is not even their intention. Rather, other procedures of cultural techniques structure how they are perceived. And it is one of these procedures - which we could call a cursory indexing, providing an overview or only a rough scan of contents - that will be the focus of this essay. ${ }^{1}$

1 In this sense, the "distant reading" devised by Franco Moretti could be understood as a nonreading, since it adopts variable macroperspectives and filters texts according to multiple unconnected aspects. Distant reading could therefore be understood as the process of encyclopedia reception, which, of course, includes the possibility of going into detail (again) at any time and, in doing so, overcoming (roughly gauging, in skipping over) vast textual distances. With a view to large, intermedial bodies of text, the question of the procedures of distant reading thus certainly makes sense, even if it would have to be treated differently than in the manner proposed by Moretti, for example, by historicizing procedures of distant reading itself. See the contribution by Toni Bernhart, “Quantitative Literaturwissenschaft: Ein Fach mit langer Tradition?” in Quantitative Ansätze in den Literatur- und Geisteswissenschaften: Systematische und historische

Translated by Michael Thomas Taylor

Ә Open Access. (C) 2020 Kristina Kuhn, published by De Gruyter. बB. BY This work is licensed under a Creative Commons Attribution 4.0 International License. 
Where does one get stuck in skipping through the pages? where does one pause? and above all, what are the structural characteristics and perceptual effects that make this happen? Which medial combinations imprint themselves or come to attention? How do they become exemplary? My contribution attempts to clarify these questions by examining the interrelationship of textuality, imagery, ${ }^{2}$ and collectivity (collectivization). It will investigate how this relationship establishes exemplarity and makes it readable, because an initial observation of this constellation reveals that the collective can only ever be represented in an exemplary way - that it requires a mode of representation-as-substitution (Stellvertretung) that makes a whole visible in an exemplar. The practices of taking an overview are forced to disregard the collective that they are supposed to make visible by providing for spatial structures of substitution.

The collective takes up the ambiguity of "collection" as a gathering together and assembling of a (social) collective - an ambiguity that arises a number of times in this volume. In the case of my material, both aspects quite evidently overlap: here, for instance, the social/ethnic collective, as well as the (specific, disciplinary) knowledge collective, are represented by a collection of images that assembles and arranges - that re-presents, in one sense, again and again, anew.

The material for my case study comes from the Bilder-Atlas zum Conversations-Lexikon (Image atlas to the conversation dictionary) published by Brockhaus between 1844 and 1875, described by its subtitle as an Ikonographische Encyklopädie der Wissenschaften und Künste (Iconographic encyclopedia of the sciences and arts). This was a kind of intermedial supplement to Brockhaus's Conversations-Lexikon (later also called the Real-Encyklopädie) - a "supplemen-

Perspektiven, ed. T.B., Marcus Willand, Sandra Richter, and Andrea Albrecht (Berlin: De Gruyter, 2018), 207-219. Even if this research is more focused on analytical techniques and tools than on techniques of reading, our task would be asking, from a historical perspective on encyclopedias, about an analogue technique of machine reading that emphasizes processes of perception and thus investigates a plurality of cultural techniques of reading. For an introduction, see Helmut Zedelmaier, "Lesetechniken: Die Praktiken der Lektüre in der Neuzeit," in Die Praktiken der Gelehrsamkeit in der frühen Neuzeit, ed. H.Z. and Martin Mulsow (Tübingen: Niemeyer, 2001), 11-30. Zedelmaier, for example, describes "Alsted's encyclopedia as a reading grid” (20), notes the recommendation of “'cursory' reading” in the seventeenth century, and interprets reading (aloud) as a kind of technique of the body that involves the entire body and can thus function to animate as well as imprint (22; with reference to Harsdörffer).

2 Sybille Krämer, Eva Cancik-Kirschbaum, and Rainer Totzke (eds.), Schriftbildlichkeit: Wahrnehmbarkeit, Materialität und Operativität von Notationen (Berlin: Akademie-Verlag, 2012). Birgit Mersmann, Schriftikonik: Bildphänomene der Schrift in kultur- und medienkomparativer Perspektive (Paderborn: Fink, 2015). This contribution is intended as an attempt to build on research into the visuality of text (image-text) by more strongly emphasizing the added value of an approach oriented towards cultural techniques. 
tary work," as it is called in the 1875 edition. I hope, however, that some of the tendencies from my observations and theses regarding this image-work can be transferred to other arrangements and series of images, and specifically to convolutes of text and image (such as image databases like Instagram that exhibit rhizomatic encyclopedic structures, as has been discussed many times in relation to the world wide web).

\section{Assembling an Atlas}

First of all, and before I go into more detail about the compositional characteristics of the Bilder-Atlas, the question arises as to its peculiar genre (if we can use that word): an atlas of images that, according to a self-description of the book contained in the 1844 edition (Systematischer Bilder-Atlas zum Conversations-Lexikon [systematic image atlas to the conversation dictionary]) ought to be systematically arranged. Robert Stockhammer has examined the atlas vogue of the nineteenth century by looking at the relationship between pictorial and cartographic representation that is eminently important for research into cultural techniques. ${ }^{3}$ The complex relationship - or, rather, reciprocal crossing - of pictorial representations and nonpictorial records provokes the question of why the atlas's form of assembling its cartographic contents (which does not actually depict anything, although it surely records things) holds such great appeal for other media. In the case of the Bilder-Atlas, would not the concept of the panorama, the album, or the catalogue all of which are forms of organization employed by the atlas on its individual pages, in its overall design, and ultimately as a bound corpus - be more appropriate?

And how is it possible to understand as systematic a catalogue of images that, as at least Gottfried Boehm's theoretical considerations ${ }^{4}$ of the images suggest, appears to completely drop out from the semantics and syntax of linguistic (even symbolic) order? The material the atlas shows on its contiguous surface, which is (usually) made up of a double-page spread, presents one more-or-less completed section. By integrating a succession of demarcated surfaces, the atlas thematizes relationships of part and whole; in its entanglement of graphic components

3 Robert Stockhammer, "Bilder im Atlas: Zum Verhältnis von pikturaler und kartographischer Darstellung," in Der Bilderatlas im Wechsel der Künste und Medien, ed. Sabine Flach, Inge MünzKoenen, and Marianne Streisand (Munich: Wilhelm Fink, 2005), 341-361.

4 Gottfried Boehm (ed.), Was ist ein Bild? (Munich: Fink, 1994); G.B., Wie Bilder Sinn erzeugen: Die Macht des Zeigens (Berlin: Berlin University Press, 2007); G.B., "Die ikonische Figuration," in Figur und Figuration: Studien zu Wahrnehmung und Wissen, ed. G.B., Gabriele Brandstetter, and Achatz von Müller (Munich: Fink, 2007), 33-52. 
(written characters, schemes, legends, illustrations), it aims to record something complete. In the geographical atlas, this something complete orbits the world or the earth (or in medieval $\mathrm{T}$ and $\mathrm{O}$ maps, even the entire cosmos of a Christian world order). Hence what claim of relating to the world does the atlas (metaphorically) represent? Does that relation to the world depend on the type of representation, on the qualities of the medium of representation? or does it depend, rather, on the subject matter of what is represented? on what is encompassed by the Atlas, representing the world demarcated by natural, geographic as well as political boundaries?

\section{Reading Images}

Beginning at least with the journal Bildwelten des Wissens (Image worlds of knowledge), ${ }^{5}$ published by the Helmholtz Centre for Cultural Techniques, the image has become a preeminent object of research into cultural techniques as visibly differing from phenomena of language or writing. ${ }^{6}$ In relation to the Bilder-Atlas, a question nevertheless arises out of the issues just discussed. Does an atlas comprised of images, or rather with individual map sheets printed with various series of images, not itself follow, in modified form, several rules of language? Or more specifically, does it not follow the rules of linguistic syntax within the representation on the material book page that has been physically opened? In the most fundamental and preliminary sense, this is the direction of reading and writing Latin script from left to right and from top to bottom - in other words: the procedures of a similar kind of cultural technique, namely, reading.

Overall, images and descriptive elements in the Bilder-Atlas are formed in many different ways: as rows of images, tableaux (some of which are panoramic representations), charts, maps, city maps, etc. The series in the later editions (1875) are often reminiscent of a mixture of photo albums and an ethnological museum

5 Horst Bredekamp et al., "Bildwelten des Wissens," in Bildwelten des Wissens: Kunsthistorisches Jahrbuch für Bildkritik, vol. 1, 1: Bilder in Prozessen, ed. Claudia Blümle, H.B., and Matthias Bruhn (Berlin: Akademie-Verlag, 2003), 9-20.

6 Of course, the problematization of this relationship is older, going as far back as Horace's ut pictura poiesis and the discussion of this notion in the eighteenth century. Accordingly, the $u t$ pictura poiesis and the Laokoon debate are to be understood as questions that are eminently related to cultural techniques inasmuch as they examine a shift in media that, at the same time, carried out a shift of dimensions: from the one-dimensionality of the oral telling of myths to the two- or three-dimensionality of the visual (plastic) arts. 
in the style of cabinets of curiosity (Fig. 1) ${ }^{7}$ : artefacts, expressions of art and cult, furniture, architecture, natural objects, and human artefacts - in short, situative, animated scenes of everyday or cultic life - appear to intermingle seemingly at random.

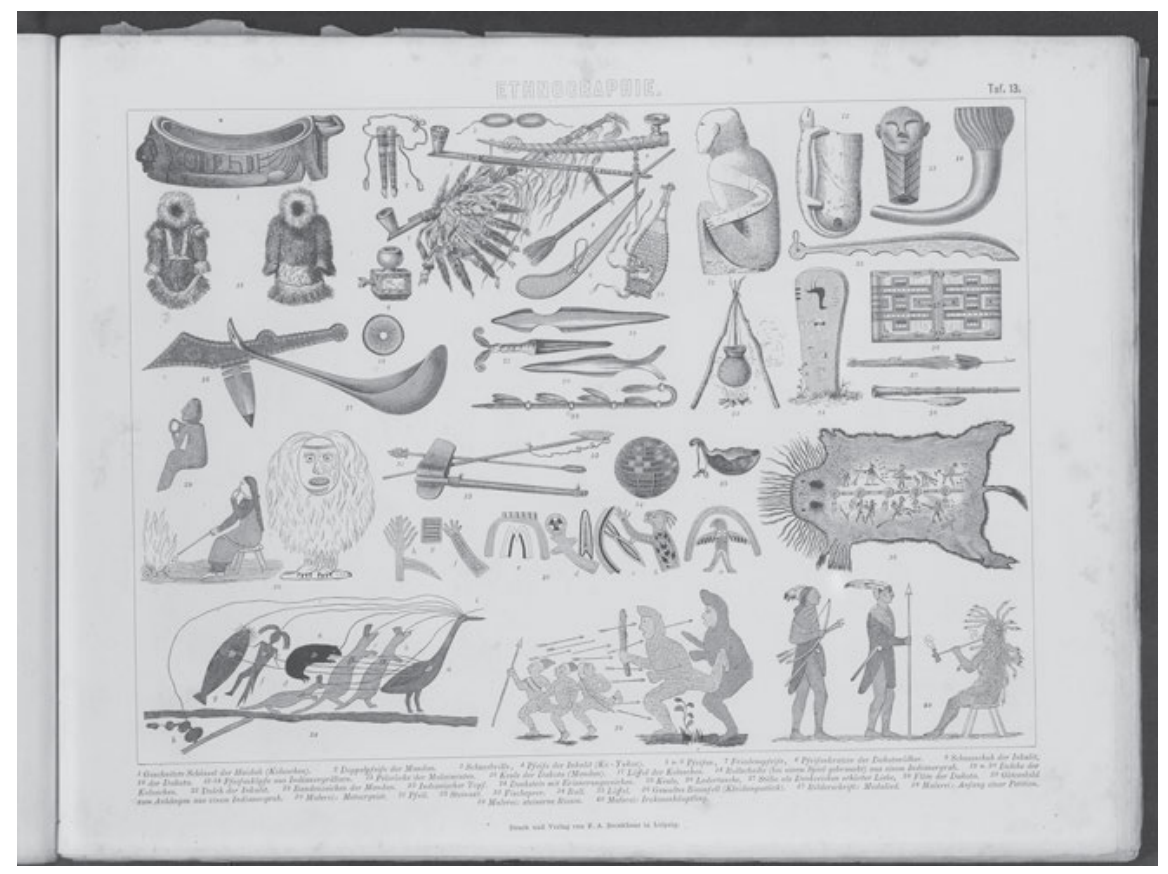

Fig. 1: Bilder-Atlas, vol. 7, Ethnographie (Ethnography), 1875, plate 13.

This is especially true for the tableau-like representations, which are found in at least two modes of imagery. On the one hand, there are images or busts surrounded by frames that identify them as images and thus immediately categorize

7 Bilder-Atlas: Ikonographische Encyklopädie der Wissenschaften und Künste: Ein Ergänzungswerk zu jedem Conversations-Lexikon, vol. 1-8, completely revised second edition, ed. Karl Gustav von Berneck, Ferdinand Bischoff, Karl Bruhns, Moriz Carriere, Bernhard von Cotta, August Essenwein, August von Eye, Wilhelm Fränkel, Georg Gerland, Wilhelm Hamm, Eduard Hartig, Rudolf Heyn, Henry Lange, Johann Müller, Bernhard Hermann Obst., Otto Prölß, Friedrich Schoedler, Julius Schott, Reinhard Schwamkrug, Alfred Stelzner, Otto Ule, Karl Vogt, Heinrich Adolf Weiske, Theodor Weiß, Reinhold Werner, and Moritz Willkomm, Fünfhundert Tafeln in Stahlstich, Holzschnitt und Lithographie (Leipzig: F. A. Brockhaus, 1868-1875), vol. 7, Ethnographie (1875), plate 13, origin of digital copy: Klassik Stiftung Weimar, Herzogin Anna Amalia Bibliothek, shelfmark: Th Q 2: 11 (g). 
them as illustrations of illustrations. And on the other hand, in the case of the artefacts, there are illustrations that find their place or fit in "directly" on the white background of the book page; they fill in gaps and thus present themselves as if on a table or in a showcase - but they do so, and this is telling, without framing. In contrast to the tableaux, other series of images are reminiscent of friezes. They essentially present individual images while often leaving open the possibility of reading the images as the continuation of a series that might even continue across multiple lines: that is, they allow the series to be read as a story told in pictures. Of course, it would be too hasty to read the Bilder-Atlas as a graphic novel. Yet, as in the graphic novel, the complex of the mutual arrangement and referencing of images and writing, as well as the difference between a strict or more free arrangement of panels, is highly relevant.

The question of image forms and designs, of their arrangements, of directions for (implicit) viewing and reading - and I am making an analogy here to the conventions of the atlas, to its legends that provide the images with paratext via tables of contents ${ }^{8}$ - opens up a far-reaching history within European-Western culture and its iconographic memory. The iconographic holdings that the Bilder-Atlas retrieves and quotes - even just those that represent "the human" - are already so diverse that they would require an art-historical analysis. ${ }^{9}$ And this is not to

8 On the concept of paratext in this sense, albeit in relation to things that have not yet been written, see Kristin Knebel, Cornelia Ortlieb, and Gudrun Püschel (eds.), Parerga und Paratexte: Steine rahmen, Tiere taxieren, Dinge inszenieren; Sammlung und Beiwerk (Dresden: Sandstein Kommunikation, 2018).

9 An associative search for earlier models would include panels since the Middle Ages depicting the Passion of Jesus; the juxtaposition of images and running text on a single manuscript page, split down the middle, of the Sachsenspiegel (between 1220 and 1235; see https://digi.ub.uniheidelberg.de/diglit/ cpg164; visited on August 6, 2019); anatomical illustrations from Vesalius's De humane corporis fabrica (1543; numerous scans can be viewed at Wikimedia: https://commons.wikimedia.org/wiki/Category:De_humani_corporis_fabrica_1543 [visited on September 9, 2019]), which founded modern anatomy; and, presumably based in part on Vesalius, convolutes of copper engravings accompanying travel literature, such as Theodor de Bry's Americae (ca. 1600; collection available from Heidelberg University Library; https://digi.ub.uni-heidelberg.de/ diglit/bry1593ga [visited on September 9, 2019]). It would also include sketches and paintings that were produced as part of James Cook's account of his voyages at the end of the eighteenth century (by Reinhold and Georg Forster, among others). See Rüdiger Joppien and Bernard Smith, The Art of Captain Cook's Voyages, vols. 1-3 (New Haven: Yale University Press, 1985-1988). I was in fact able to identify several motifs either from or following Sydney Parkinson (Tahiti, New Zealand) in the Bilder-Atlas that exist - presumably after multiple instances of copying - unmarked between stocks of images of other provenances. See also Joppen and Smith, The Art of Captain Cook's Voyages, vol. 1 (several pictures) with Brockhaus's Bilder-Atlas (1875), vol. 7: "Ethnographie," plate 6 (see note 7 ). 
mention the volumes of the Bilder-Atlas dedicated to art history and the history of technology as such, which would certainly be unthinkable without the volumes of plates in the French Encyclopédie edited by Diderot and d'Alembert, though this is a comparison I cannot pursue here.

In viewing the images of the Bilder-Atlas from the perspective of cultural techniques, my concern here is less with possible iconographic traditions, stocks of motifs, and their citation or modification through replication. The constraints and conditions of a commercial image archive and its purposes of conservation and reproduction, which would render plausible the recycling of stocks of images in different contexts, must also be left aside here - even though these pragmatic factors of visual economics or politics are insightful from the perspective of cultural techniques.

In taking such a perspective, I will focus instead on the highly complex relationships and arrangements of text and image in the Bilder-Atlas, which change over the course of the work's three editions from 1844 to 1875. This begins with a brief listing of the plates in tables of contents, complemented in part by volumes commenting in text on each individual volume of plates (1860). Thus degraded to text supplements of the visual supplement to the lexicographical main work, these texts then develop a life of their own. In the next edition (1868-1875), textual elements become more or less extensive image captions making it possible to immediately decipher the images without leafing back and forth in the book or even different volumes. Obviously, it is difficult to follow the text-image references when they are printed relatively far apart, for example, if a reader must connect the table of contents listing different sections (fields of knowledge) and its numbered designation of plates to the subsequent image catalogue that is meant to be browsed (since it has no page numbers); or even in tracing the references between the table of contents, the image catalogue, and the textual commentary that is also structured according to the rationale of sections of knowledge. As noted above, these are not so much commentaries as independently readable volumes of text that essentially function without the illustrations in the atlas they are actually meant to explain. Perhaps because this made it more difficult to read and scan the images, the 1875 edition of the Bilder-Atlas increasingly makes use of direct captions in the lower area of each individual page. But even in this case, what is depicted is by no means self-evident.

On the contrary, the images - in combination with their captions and the additional section titles - develop emblematic structures suggesting a message alongside what is shown that is itself, at least, not meant to be read in one, irreversible linear direction or as unambiguously descriptive. Rather than standing in linear relationship structures to each other, the various elements of text and image superimpose different moments of order that overlap, comment upon, and contradict each other. 
In this essay, I will thus focus on exemplarily variable directions of reading in the images in the atlas. I would describe these as emblematic and narrative modes to read, i.e. to perceive a book page in its visual appearance, with the assumption that "reading" indicates more than a mere metaphor of interpretation, to then relate them to the setting of the collective. I will argue that the reading paradigm (and syntagm) is decisive for a notion of the images. It determines (or makes possible) different directions for seeing the images; it in part creates their visibilities in the first place. A mode of assembly or compression, ${ }^{10}$ in the manner characteristic for museums of the nineteenth century, inserts itself here between emblematic and narrative interpretation, although it seems to me that this mode already undergoes a transformation in the short phase between 1860 and 1875.

\section{Seeing the Exemplary: "Die Völker Europas" (The peoples of Europe), plate 110}

How are the (assembled) collections of various collectives structured in the atlas? One page that can be taken as emblematic, as it were, for the collection process in the Bilder-Atlas comes from the section on Völkerkunde der Gegenwart (Völkerkunde of the present) (Section 4) from 1860 (Fig. 2) ${ }^{11}$ It shows, in three rows stacked horizontally, different types of peoples or ethnic groups in smaller groups, mostly in arrangements of two or three facing each other, that form a common space. (Brockhaus, however, would only publish a volume on the discipline of "Ethnographie" - as opposed to the early discipline of "Völkerkunde" with the seventh volume of the Bilder-Atlas from $1875 .^{12}$ )

10 Annette Graczyk, Das literarische Tableau zwischen Kunst und Wissenschaft (Munich: Fink, 2004) has reconstructed the transitions in the tradition of the tableau from the theatrum to the museum; see 14, 29, 35.

11 Bilder-Atlas zum Conversations-Lexikon: Ikonographische Encyklopädie der Wissenschaften und Künste, vol. 1-10, ed. Johann Georg Heck, 500 Tafeln nebst Text und Universal-Register, fifth edition (Leipzig: F. A. Brockhaus, 1860), vol. 4, Völkerkunde der Gegenwart, 42 Tafeln nebst Text, plate 110 (1), origin of digital copy: Klassik Stiftung Weimar, Herzogin Anna Amalia Bibliothek, shelfmark: N 15667 (f).

12 The discipline of "Völkerkunde" emerged in the nineteenth century as a study of "peoples" that only later developed into the twentieth-century disciplines of ethnography and ethnology. Its methods were closer to what we would today call cultural anthropology. This differentiation is crucial for my argument in this essay. 


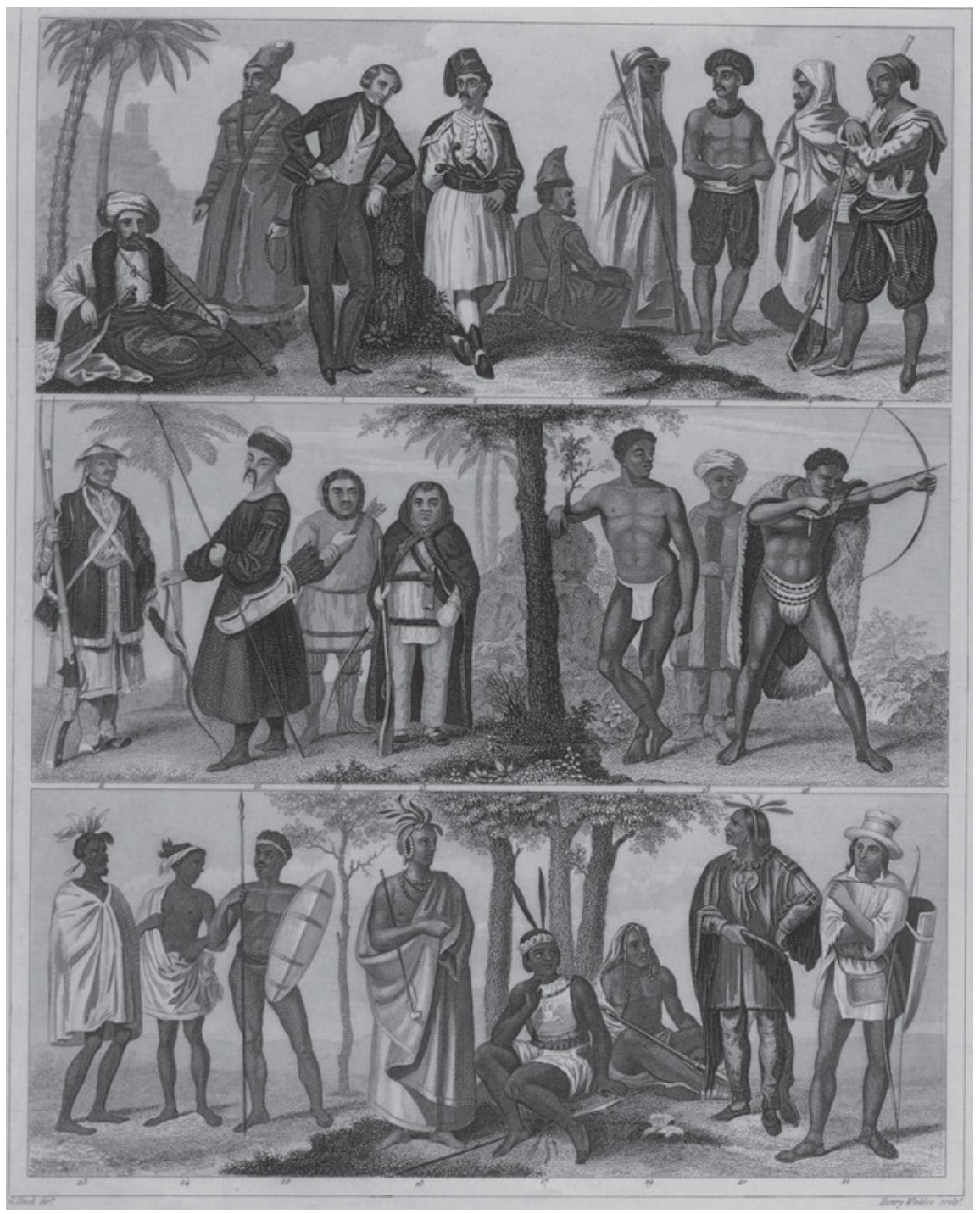

Fig. 2: Bilder-Atlas, vol. 4, Völkerkunde der Gegenwart (Völkerkunde of the present), 1860, plate 110 (1).

The convention of the book and its rules of reading, from left to right and from top to bottom, seems to require that we dissolve the rectangular space of the page into three rows, but there is nothing preventing a reader from dissolving the three horizontal rows into a continuous single row - or perhaps there is? The individual figures in the course of the series are numbered consecutively so that 
their denominations can be assigned within thematic subgroups using the table of contents. The numbering does not enumerate the figures in ascending order but seems to follow the inner requirements of the representation that gives the groupings their own regularity. The appearance of grouping results from natural elements, such as shrubs, trees, and rocks, that provide structure in dividing the continuous natural space. The space shown is a land-space through and through, which is striking in that the grouping/dividing element of the world's continents seems rather to slip away as something fluid.

Two principles of order overlap within this linear arrangement of groups of figures, legible as both a spatial continuum and as interior spaces. On the one hand, if one reads the rooms of the world represented by the groups of figures depicted in rows as a map of the earth, there is a (roughly traced) geographically contrary movement from west to east, from east to southeast, from southeast to northwest, and back again to southeast. Or one can follow the directional movement from west to east to southeast beyond the map border to north and then again in southeasterly direction as a diagonal from top left to bottom right, following the line break or change of direction starting again at top left, and from there again to bottom right as the (Eurocentric) direction of reading, which would also trace a (diagonal) circumnavigation of the globe, provided that the change of direction goes beyond the lower right border of the world map. In both cases, the direction begins with a Eurocentric starting point, the old world of antiquity, to then pass through the old world of Asia and Africa to the New World (Australia and America).

And on the other hand, there is a division of "tribes" (see the "Verzeichniß der Erklärung der Abbildungen" [Index of figure captions], in the table of contents after the title page) in a system organized according to "five main races," which are embedded in the two parallel west-east/east-west/west-east or north-south/southnorth/north-south orientations, or the diagonal movement over the globe from left to right and from top to bottom, which makes it unnecessary to indicate the cardinal direction. The representation of the globe thus overlaps with the cartographic representation of the world map within the system of the reading directions of the Latin alphabet. Therefore, for this page of the Bilder-Atlas, the template or metaphor of the atlas, or even of the globe, proves to be quite justified, since the series of images are in fact structured according to a cartographic order. The sequence of continents is based on the established cartographic regime of nineteenth-century European atlases: Europe, Asia, Africa, Australia (New Zealand), and America.

Ironically enough, in the Eurocentric arrangement the "Uebersichtsblatt der fünf Hauptracen" (Overview page of the five main races) forms a subitem under the heading "Die Völker Europas" (The peoples of Europe), thus failing to conform to the originally announced order - probably because this volume of the Bilder-Atlas largely offers an ethnography of Europeans themselves. In addition, a 
marker of civilization has been registered upon the "Uebersichtsblatt" (overview page), insofar as the first upper row, in addition to the extremely barren natural structural elements, is the only one with an architectural background (a keep). The order of "five main races" entered in the index is also superimposed or overdetermined by another designation system, namely by the inclusion of "national costumes," which registers a greater variety of distinguishing features, and not only within the "races" that cannot be integrated into this racial "system."

What is collectively assembled by the series of images and plate legends are not primarily the various "races" and ethnicities of the world - which are abridged or incomplete in any case in relation to each of the recorded characteristics, whether it be "national costumes" or "races." Rather, what is assembled are parallel possibilities of order, oriented toward disciplines of knowledge, and partially determined in terms of media: for geography, this is the globe or map; for anthropology, theories of race or ethnicity; for politics, national or local; and for history, cultural and social history or art history. The (disciplinary, thematic) knowledge collective shows not only what it shows but above all what it produces and how it is produced.

The sequence allows for various options of pursuing the collective as a linear continuum, of dividing it into geographical areas along the breaks of the line transitions or other structural elements, or of unfolding the movement globally across the regions of the world.

Because the first row lacks structuring natural elements, it evinces a higher degree of continuity, which simultaneously entails a stronger individualization of the figures. As a continuous space, the first row outlines the geographical world of antiquity in dimensions that are still the basis of most maps of Europe today. The figures in the second and third rows tend to be grouped, while more or less sharply distinguishing one group from another. Interaction almost seems possible between grouped figures, tending to offer narrative (or at least imaginary) potential. The separating elements of nature, which create a (partially) common background to begin with, i.e., a background separated from the other elements, create a connection within groups (which they thus constitute in the first place) and feign a proximity within or between them that is neither spatial, temporal, nor social (the rows produce dislocations and anachronisms). The figures standing in as representatives of their "tribe," of nations or regions, of their "estates" or their social "[c]lass," form internal collectives, while also themselves exemplifying a collective. The exemplarity of the individual figures on the page, by contrast, is highly dependent on the supplementary explanation of the plate, since the attributes given to identify the figures are only readable in combination with their designation. Viewed in isolation, attributes such as clothing, headdress, tools (weapons), or physique seem less specific; and the less dressed the figures are, the less they are characteristic. 
Exemplarity consists less in or results less from a catalogue of characteristics that could refer to one single generality, since the respective generality is split up into different generalities by the various systems of systematization, discourse networks, representation, and reading. Rather, what is meant to be general is indicated by a single designation in the table of contents or image captions. The characteristics of visible attribution, for their part, again contribute to larger internal collectives, which form, through mutual reference, a larger collective (within the system of tribes). They do not, however, stand as specific within this larger collective; rather, they function within the collective to introduce minimal differences. Hence it is not only collectives of different sizes, or more or less comprehensive collectives, that are shown - starting from the exemplary type representing and substituting for parallel collectives (a region, nation, "class," or the wearers of a certain ethnic costume); or then as an individual who is in turn integrated into the larger collective of "races" (or even "main races") or of a "tribe"; in order to finally enter the collective of world citizens by overcoming all borders.

Rather, the naive-looking illustrations of the series accord with horizons of diverse knowledge and world systems that by no means intermesh in any contained way or prove to be self-contained. The Bilder-Atlas not only hints at various collectives but also presents various modes of collection. Who or what is exemplary is permanently reorganized within different assemblage-collections, which is what gives it the status of an exemplar to begin with. The individual exemplar (or exemplum) establishes less a relation to the general than it is taken out of a larger collective to be inserted into another one. With reference to the largest collective visible on the page, the assembly of world citizens, which stretches between the co-presence of linearity and flatness, the question naturally arises of whether there can be an equal arrangement of difference. The parallel diversity created in the spatially movable arrangement acts out conflicting world orders on the layout of a page.

It may be plausible to speak of emblematic structures on the plate analyzed here that enable parallel interpretations of overlapping orders of inscriptio, subscriptio (in image headings or captions and in indexes) and pictura (or perhaps: motivic allusions similar to those in emblem books), and that do not come together to form an overall interpretation but rather open up a disciplinary field from geography to cultural history. At the same time, this can be linked to two further types of image collections (or assemblages) that follow other spatial orders and thus paths of reading: narratively structuring series of pictures, such as the depiction of Egyptian life from the 1875 volume on Culturgeschichte (Cultural history) (Fig. 3), as well as an example from the volume on Ethnographie (Ethnography) 
(also from 1875) (see Fig. 1), which looks like a museum assemblage on paper. ${ }^{13}$ In both cases we are apparently dealing with quite different systems of order, but also with image effects.

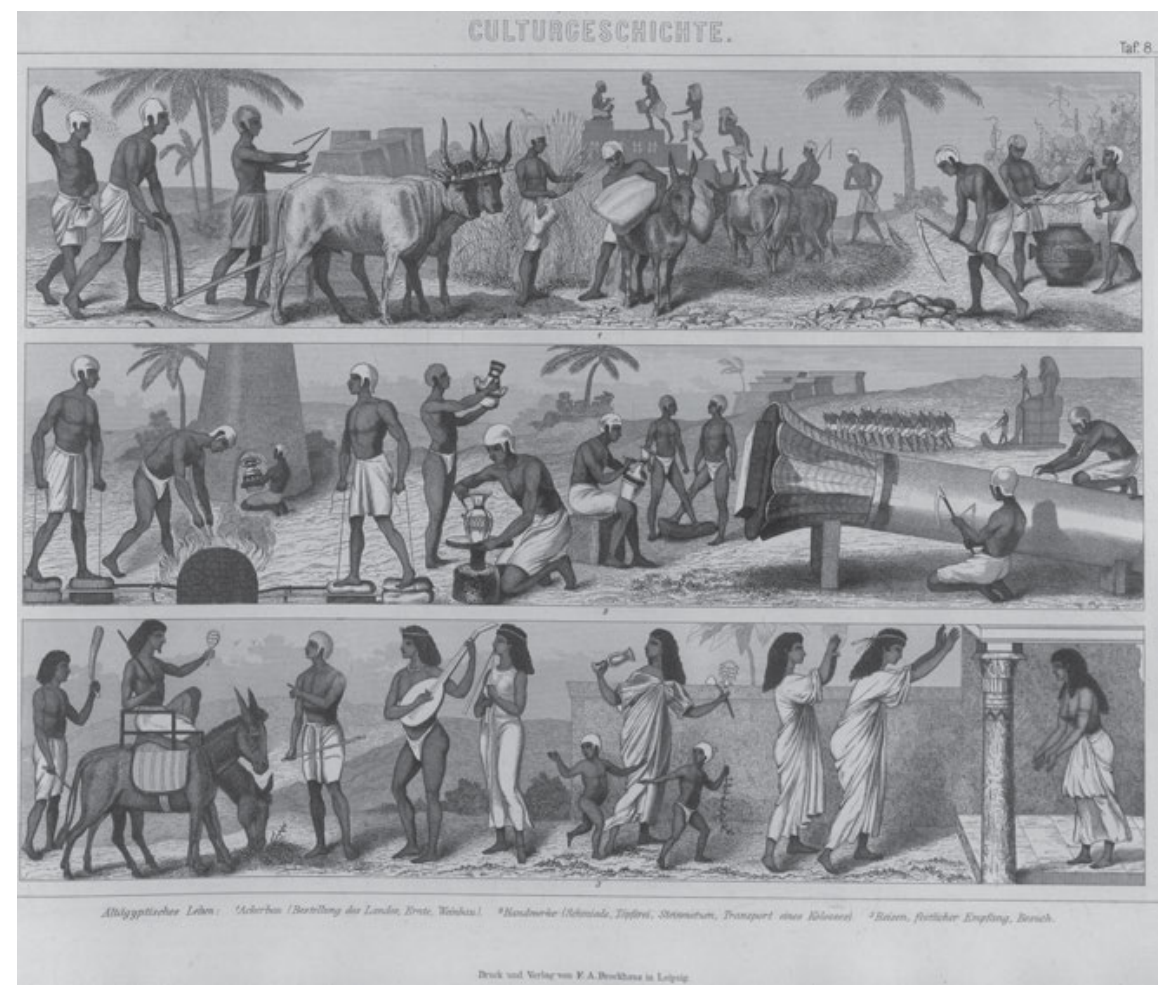

Fig. 3: Bilder-Atlas, vol. 6, Culturgeschichte (Cultural history), 1875, plate 8, “Altägyptisches Leben" (Ancient Egyptian life).

The page of Völker der Welt (Peoples of the world) (Fig. 2) I am analyzing here comes from the volume of the Völkerkunde der Gegenwart (Völkerkunde of the present) published in 1860 (Section 4); Section 3 of this issue contains a volume on Geschichte und Völkerkunde (History and Völkerkunde). Here, too, the duplication of the modes of order seems to shift time and space against each other and mix them together: (namely) a contemporary and a historical ethnography. Both sections

13 Bilder-Atlas, vol. 6, Culturgeschichte (1875), plate 8, “Altägyptisches Leben”; Bilder-Atlas (1875), vol. 7, Ethnographie, plate 13 (museum assemblage). 
(volumes) are no longer found in the 1875 edition of the Bilder-Atlas. They are replaced by volumes 6 and 7 of the newer edition, published just fifteen years later, which divide the body of ethnographic knowledge ("Völkerkunde") into a scientifically timeless subject, "ethnography," and the (newly emerging) discipline of "cultural history." It seems obvious that this form of division and scientification of the collections (which do not appear so dissimilar when one compares the museum-like illustrations) responds to the problem of the superimposition of the axes of time, space, and knowledge, which itself takes recourse to an earlier and outdated understanding of knowledge that did not meet (or no longer met) the scientific expectations of the late nineteenth century.

The coordinates given by the epistemic order of the atlas thus describe something outdated, a thing of the past. The Bilder-Atlas generates (especially in its individual thematic volumes) internal collectives of knowledge; however, it thereby replaces the reference to something complete with an (apparent) system of scientific disciplines that renders this recourse obsolete. In this respect, it is only logical that the images of the Atlas are integrated into the Real-Encyklopädie as figures (beginning in 1882), where they take on a largely illustrative character without developing their own image-worlds. The reciprocal superimposition of knowledge arrangements able to take shape in the specific spatial arrangement of the work's collection of text and image is no longer desired in the Reallexikon; these images now function as a supplement, while the primacy of text serves to discipline the stock of knowledge. As a leading medium, text marginalizes the refuge of the imaginary that the image-supplements open up in the first place. 